\title{
Thermal Compensation and Fuzzy Control for Developing a High-Precision Optical Lens Mold
}

\author{
Chung-Ching Huang, Fu Zhang and Yi-Jen Yang \\ Department of Mold and Die Engineering, National Kaohsiung University of Applied Sciences, Kaohsiung 807, Taiwan, ROC
}

\begin{abstract}
Precision plastic lenses often exhibit dimensional deviations due to the thermal expansion of the mold during injection molding. Although this deviation is smaller in micron-sized $(1-5 \mu \mathrm{m})$ lenses, it exceeds the tolerance requirement of such lenses. It is difficult to resolve this dimensional issue by using injection molding parameters (e.g., melt temperature, injection speed, and hold pressure). In this study, the thermal analysis of a mold was conducted, and it was confirmed that the deviation of lens dimension was caused by the thermal instability and thermal expansion of the mold. Due to the inconsistent heat distribution of the fixed and the movable side of the mold, the position of the location system was displaced approximately 1 to $5 \mu \mathrm{m}$. In this study, thermal compensation technology for this the mold was investigated. The temperature on both sides of the mold was measured, and mold temperature could be adjusted automatically using a control strategy based on fuzzy theory. During the mold preheating or mass production stage, the temperature on both sides of the mold could be easily adjusted to quickly obtain the required temperature range. The dilatation on both sides of the mold was revised to improve the alignment accuracy of the cavity, and the decenter error of these injection lenses was reduced to $1 \mu \mathrm{m}$. This technology can markedly improve the production yield and efficiency of plastic products requiring an extremely high dimensional accuracy.
\end{abstract}

Key words: Fuzzy control, temperature compensation, decenter error.

\section{Introduction}

Recently, with the considerable increase in demand for injection molding, related products are generally short, small, light, and thin, and injection molded with high precision. This enables the accurate production of optical lenses. Precision injection molding is essential in manufacturing small and precise plastic lenses for phone cameras. Numerous critical factors must be satisfied to meet the requested specifications of high-quality plastic lenses. Severe tolerance limits are required to ensure such optical lenses are of a high quality. Moreover, product quality is affected by the displacement and deformation of the mold used [1]. The most common causes of mold deformation are derived from pressure, temperature [2]. ANSYS (ANSYS, Inc.) was used to analyze mold deformation when it was subjected to a high pressure [3], and large

Corresponding author: Yi-Jen Yang, Ph.D. student, research field: plastic processing. displacement of the mold was generated using thermal-structural coupling analysis. The thermal expansion of a mold is the crucial factor in minimizing the decenter error.

Herein, the decenter error of a precision plastic lens was taken as the main quality index and molding conditions were discussed to evaluate the influence of eccentricity. Two temperature controllers were employed for the mold. Mold expansion effects were observed after temperature modification. According to the effects of mold temperature modification on mold expansion, when mold temperature is controlled using fuzzy theory [4], the decenter error is reduced to achieve lens eccentricity.

The fuzzy theory, first proposed by Zadeh [4] from the University of California, Berkeley in the United Sates, combines the experience and intellectual reasoning process of human beings. It directly applies to controllers, and can indirectly reduce reliance on mathematical models. This method is markedly beneficial for the control of uncertain processes in 


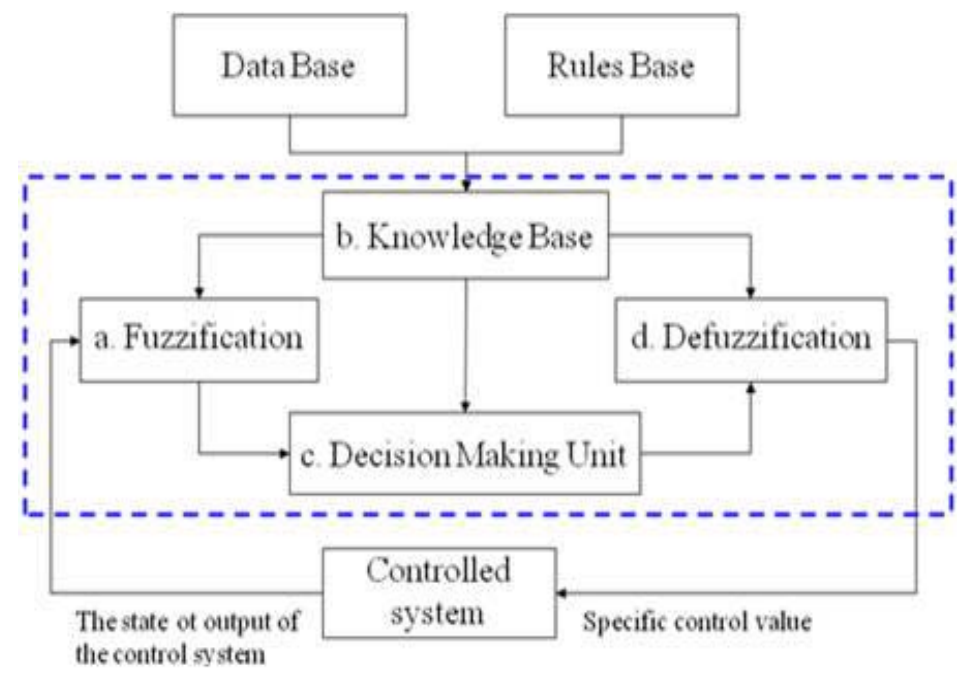

Fig. 1 Basic structure of the fuzzy control process.

studies [5-7]. The basic structure of a complete fuzzy logic control system is shown in Fig. 1.

\section{Research Method}

Polyester (OKP optical plastic) (OSAKA GAS CHEMICALS-OKP1) was used for analysis, which is an amorphous material with a flow index of $250 \mathrm{~g} / 10$ $\min$ at $250^{\circ} \mathrm{C}$ for a load of $2.16 \mathrm{~kg}$. The mold material used was M333, which exhibits excellent polishing ability machinability, and high-temperature corrosion resistance, in addition to favorable wear resistance. The insulation plate used was composed of glass fiber, which was employed to avoid transferring heat from the mold to the injection molding machine.

The study materials consisted mainly of a cold runner mold and a 16-cavity aspheric plastic lens (Fig. 2). The models for mold flow (MoldFlow, Autodesk Inc.) and structural (ANSYS, ANSYS Inc.) analyses are presented in Figs. 3 and 4, respectively. The ejection system of the mold was not considered in the structural analysis model, but the insulation plate and the fixed and moved plates of the injection molding machine were.

The decenter error of a lens is calculated by measuring the center axis displacement and tilt angle of the lens. In this study, a decenter error was generated and considered as the center axis displacement of the lens (Fig. 5). The eccentricity of the lens was affected by product design, mold design, process parameters, and mold deformation. The pressure and thermal expansion of the mold were the main influencing factors for mold deflection. The experiment was conducted in three stages without considering product or mold designs. First, computer-aided engineering (CAE; Moldflow) was used to analyze the effects of molding parameters on lens eccentricity. In the second stage, the influence of molding parameters on volume shrinkage was determined through a single factor experiment. The injection molding parameters are presented in Table 1.

Third, CAE (ANSYS) was used to analyze the effect of mold deformation on lens eccentricity. Optimal control factors of mold deformation for eccentricity and control specifications were investigated. The decenter error can be controlled within the range of $\pm 1 \mu \mathrm{m}$ using fuzzy control to compensate for changes in mold temperature. The boundary conditions for the CAE analysis are shown in Table 2.

The volume shrinkage of each node can be calculated using mold flow analysis. Ten nodes were employed to calculate the average and differences (standard deviation) between the volume shrinkage value obtained from each node 

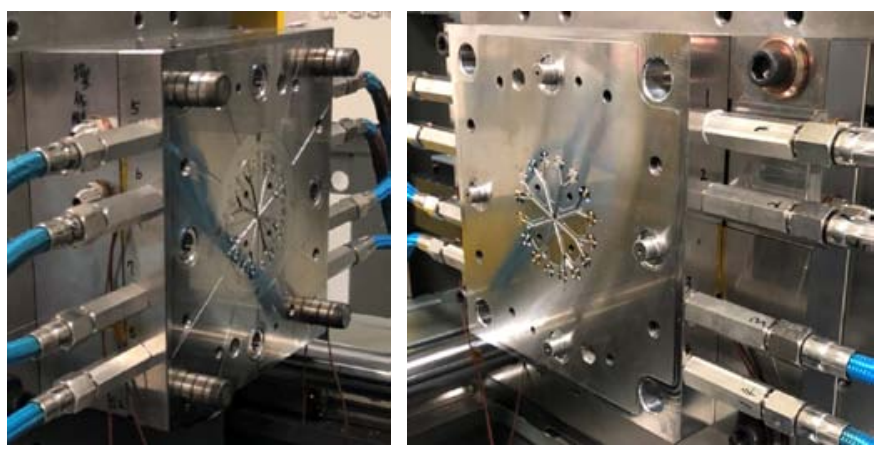

Fig. 2 A 16-cavity injection mold.

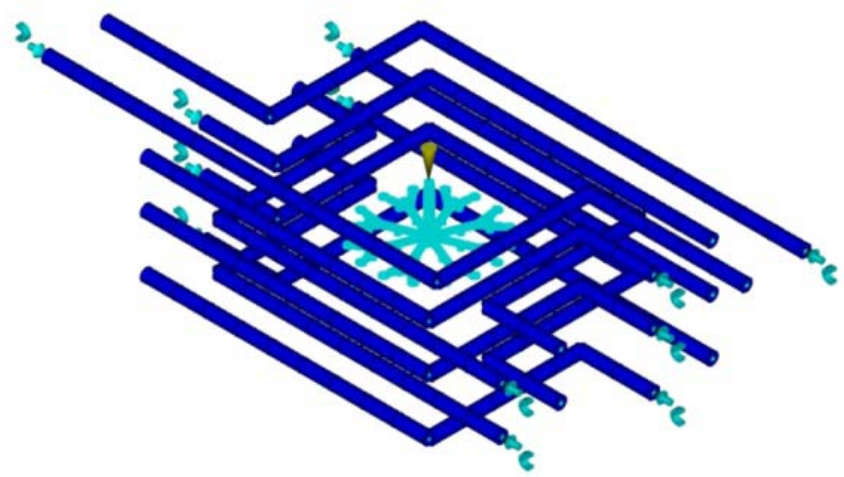

Fig. 3 Moldflow analysis model.

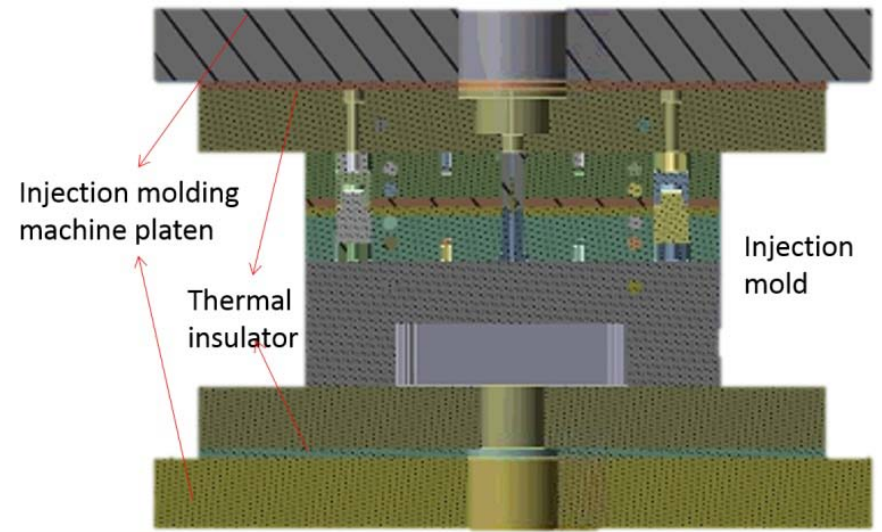

Fig. 4 Model of ANSYS structure analysis.

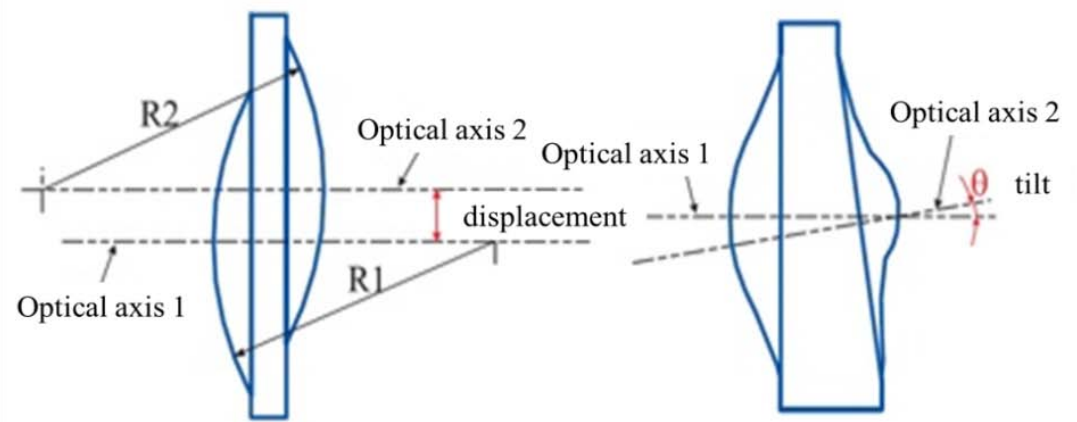

Fig. 5 Decenter error of an aspheric lens. 
Table 1 Injection molding parameters.

\begin{tabular}{ll}
\hline Mold temperature $\left({ }^{\circ} \mathrm{C}\right)$ & $90 / 110 / 130$ \\
\hline Melt temperature $\left({ }^{\circ} \mathrm{C}\right)$ & 270 \\
\hline Packing pressure $(\mathrm{MPa})$ & $10 / 55 / 100$ \\
\hline Packing time (s) & $0 / 2.5 / 5$ \\
\hline Cooling time (s) & 15 \\
\hline
\end{tabular}

Table 2 Boundary conditions for ANSYS analysis.

\begin{tabular}{ll}
\hline Ambient temperature & $25^{\circ} \mathrm{C}$ \\
\hline Initial temperature & $25^{\circ} \mathrm{C}$ \\
\hline Air heat conduction coefficient & $0.026 \mathrm{~W} / \mathrm{m}-\mathrm{K}$ \\
\hline Coolant temperature of the moved & $90 / 95 / 100 / 105 / 110 / 115 /$ \\
plate & $118.3 / 125 / 130{ }^{\circ} \mathrm{C}$ \\
\hline Coolant temperature of fixed plate & $100 / 105 / 110 / 115 / 118.3 /$ \\
& $125 / 130{ }^{\circ} \mathrm{C}$ \\
\hline Maximum cavity pressure & $55 \mathrm{MPa}$ \\
\hline Initial mold temperature sprue & $271^{\circ} \mathrm{C}$ \\
\hline Initial mold temperature runner & $273^{\circ} \mathrm{C}$ \\
\hline Initial mold temperature cavity & $275^{\circ} \mathrm{C}$ \\
\hline Injection time & $0.2 \mathrm{~s}$ \\
\hline Mold opening time & $5 \mathrm{~s}$ \\
\hline
\end{tabular}

The method for determining the displacement of the central axis of the lens is shown in Fig. 6. Nodes a, b, and $\mathrm{c}$ and $\mathrm{d}$, e, and $\mathrm{f}$ were obtained at the circular feature positions of lenses S1 and S2, respectively.

S1

Circular feature location
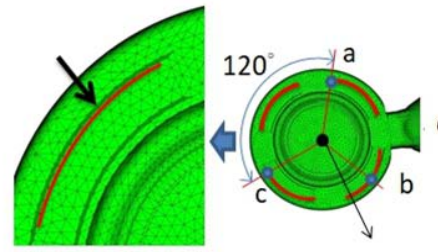

Center
The angle between each node was $120^{\circ}$, and the coordinates of nodes $\mathrm{a}, \mathrm{b}$, and $\mathrm{c}$ and $\mathrm{d}$, e, and $\mathrm{f}$ were respectively used to calculate the center coordinates of S1 and S2, and the decenter error of the lenses was calculated using the obtained center coordinates.

The method for determining mold eccentricity is presented in Fig. 7. The nodes in the center of the S1 and S2 lenses on the mold were set to calculate the mold eccentricity by measuring the deformation position of these lenses. The decenter error is positive when the moved plate expands more than the fixed plate and negative when the opposite occurs.

Four temperature sensors were installed in the mold, and the positions of these sensors are displayed in Fig. 8. Mold temperatures were monitored to investigate the relationship between coolant temperature, average temperature of the fixed plate and moved plate, mold temperature difference and the decenter error. The average temperature of the fixed plate, moved plate, mold temperature difference $\Delta \mathrm{T}$, and average bulk temperature are calculated as below:
S2

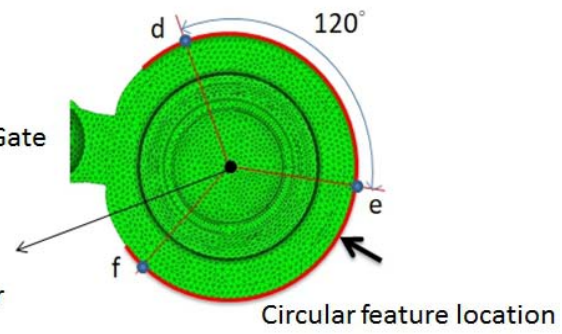

Fig. 6 Decenter error calculation with Moldflow analysis.
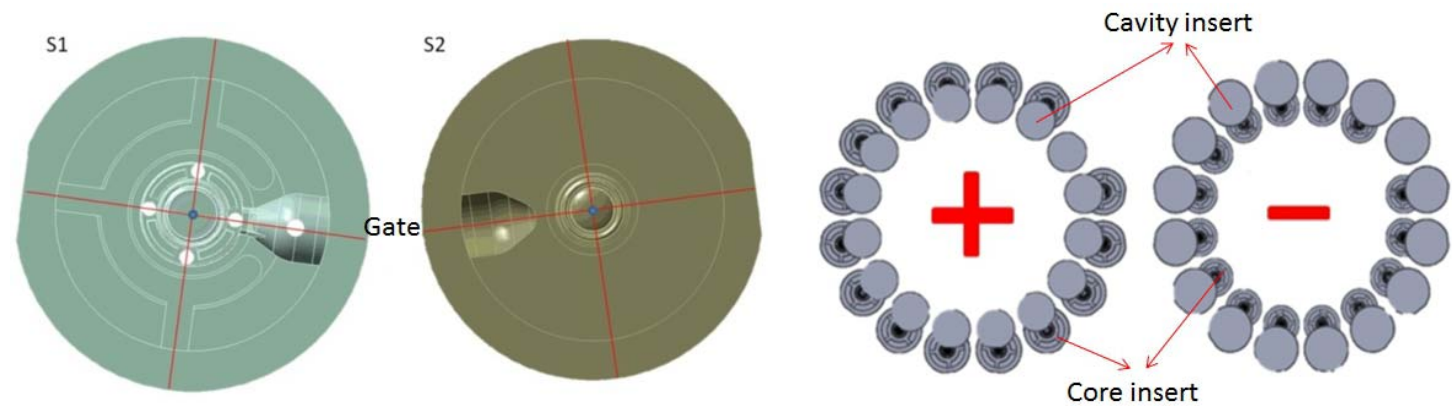

Fig. 7 Decenter error calculation with ANSYS analysis. 

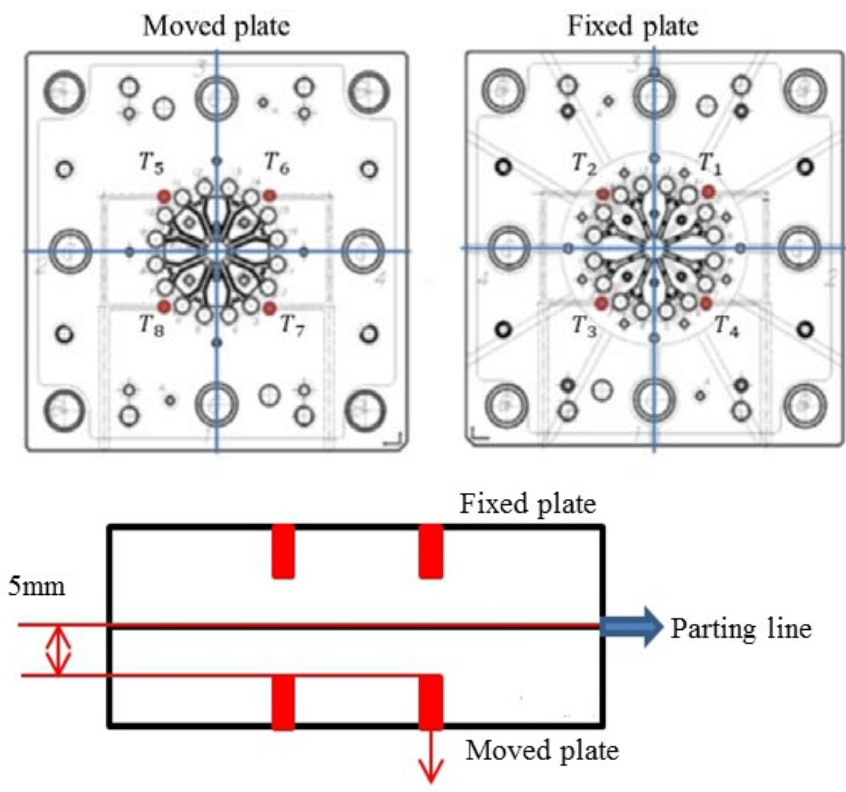

Temperature sensors $\times 8$

Fig. 8 Positions of temperature sensors.

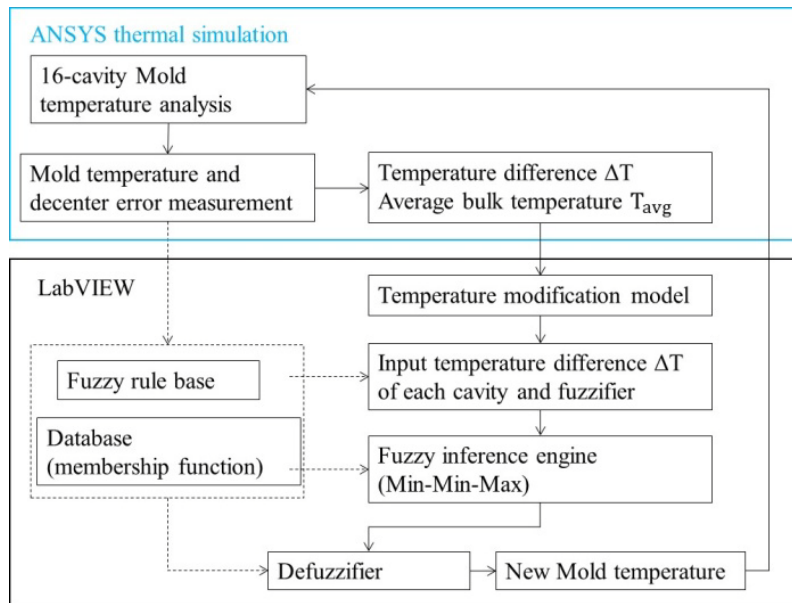

Fig. 9 Thermal compensation system.

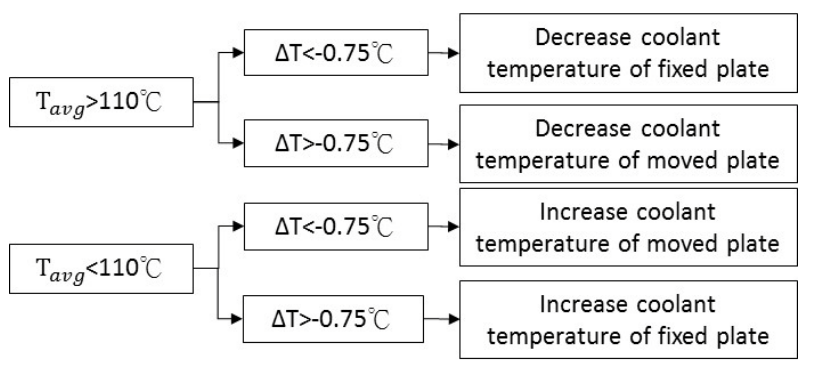

Fig. 10 Temperature modification model.

Average temperature of the moved plate $T_{A}$ : $\frac{T_{1}+T_{2}+T_{3}+T_{4}}{4}$

Average temperature of the fixed plate $T_{B}$ :
$\frac{T_{5}+T_{6}+T_{7}+T_{8}}{4}$

Mold temperature difference $\Delta \mathrm{T}: T_{A}-T_{B}$

Average bulk temperature $T_{\text {avg }}: \frac{\mathrm{T}_{\mathrm{A}}+\mathrm{T}_{\mathrm{B}}}{2}$

The thermal compensation system, illustrated in Fig. 9, is composed of mold thermal analysis and mold temperature fuzzy control systems. In this system, after the completion of the thermal analysis, $\Delta \mathrm{T}$ is calculated. $\Delta \mathrm{T}$ can be applied to perform fuzzy reasoning. Subsequently, defuzzification is employed to output a specific control value in order to modify the mold temperatures, which depend on the temperature modification model shown in Fig. 10.

\section{Results and Discussion}

\subsection{CAE Analysis}

(1) Effects of process parameters

Moldflow analysis results are shown in Figs. 11 and 12. The symmetrical shape and small size of the lens resulted in an unobvious shrinkage difference compared with other lenses. The volume shrinkage increased a higher mold temperature and holding pressure. The gate was frozen in $2 \mathrm{~s}$, and the volume 
shrinkage was not influenced by a longer packing time. The shrinkage difference (standard deviation) at different positions was small, indicating that the lens exhibited a uniform volume shrinkage.

The decenter error increased with increase in mold temperature. The high volume shrinkage was caused by a 0 -s packing time, and the higher decenter error was caused by a higher mold temperature. The high decenter error was not caused by the high volume shrinkage.

(2) Effects of the thermal expansion of the mold

The thermal expansion analysis (Figs. 13 and 14) revealed that the decenter error increased when there was a high coolant temperature difference in the fixed and moved plate. A higher mold temperature difference $(\Delta \mathrm{T})$ caused a higher decenter error. For example, when the respective coolant temperatures of the moved and fixed plate were 90 and $130{ }^{\circ} \mathrm{C}$, the mold temperature difference and decenter error were $-2.5{ }^{\circ} \mathrm{C}$ and $-2 \mu \mathrm{m}$, respectively. The coolant temperature of the moved plate was constant, and that of fixed plate increased by $5{ }^{\circ} \mathrm{C}$, resulting in a mold temperature difference of $0.3 \quad{ }^{\circ} \mathrm{C}$. By contrast, lowering the coolant temperature of the fixed plate by $5{ }^{\circ} \mathrm{C}$ resulted in a mold temperature difference of $+0.3^{\circ} \mathrm{C}$. Similarly, when the coolant temperature of the fixed plate was constant, the coolant temperature of the moved plate increased by $5{ }^{\circ} \mathrm{C}$, resulting in a mold temperature difference of $0.3{ }^{\circ} \mathrm{C}$. When the coolant temperature of the fixed plate was constant, lowering the coolant temperature of the moved plate

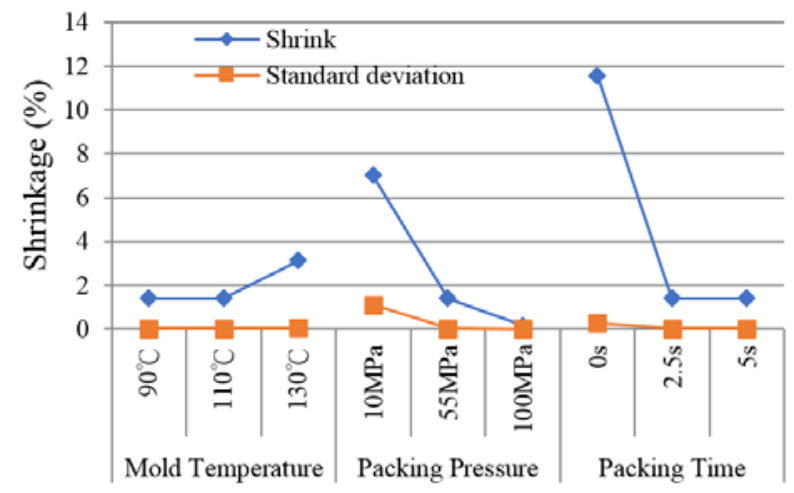

Fig. 11 Volume shrinkage with molding parameters.

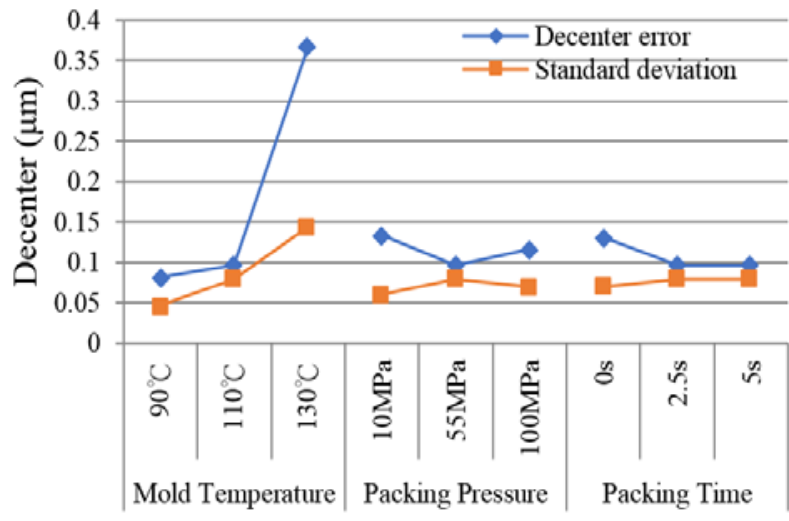

Fig. 12 Decenter error with molding parameters.

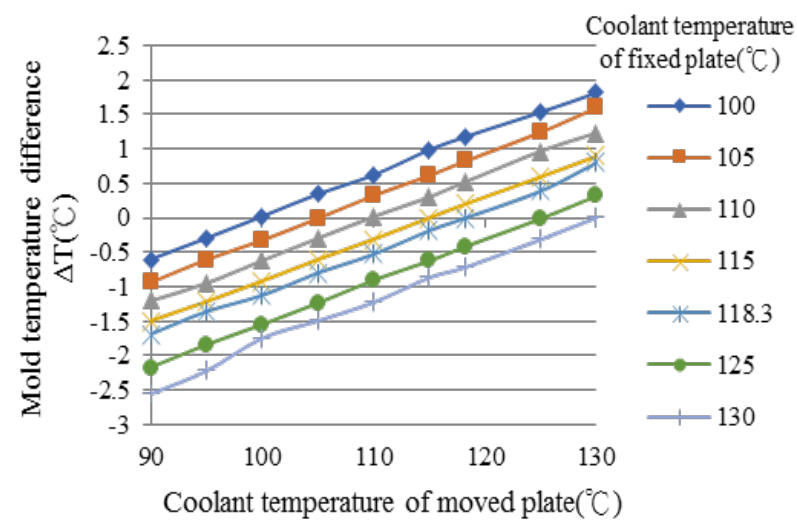

Fig. 13 Effect of coolant temperature on mold temperature differences.

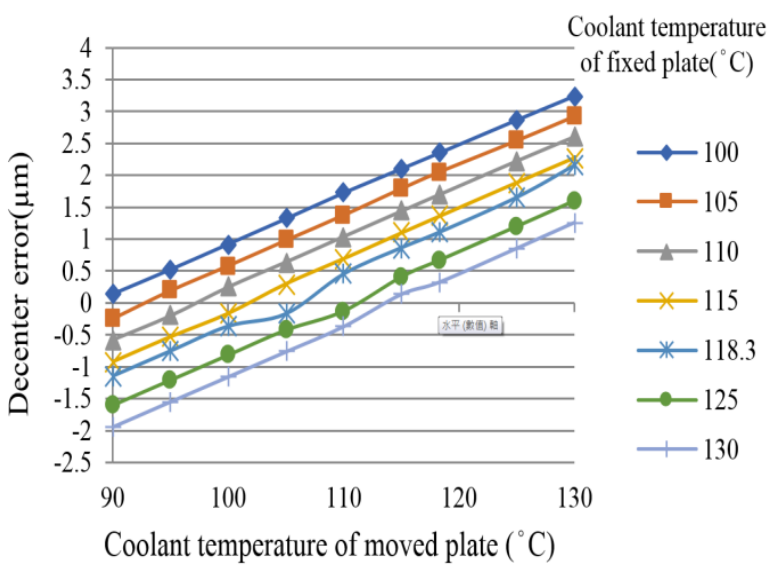

Fig. 14 Effect of coolant temperature on the decenter error.

by $5{ }^{\circ} \mathrm{C}$ resulted in a mold temperature difference of $-0.3^{\circ} \mathrm{C}$. The coolant temperature of fixed and moved plates can be altered to obtain a mold temperature difference within the range of $-1{ }^{\circ} \mathrm{C}$ and $-0.5^{\circ} \mathrm{C}$, and the decenter error can be controlled within the range of -1 and $1 \mu \mathrm{m}$ (Fig. 15). 


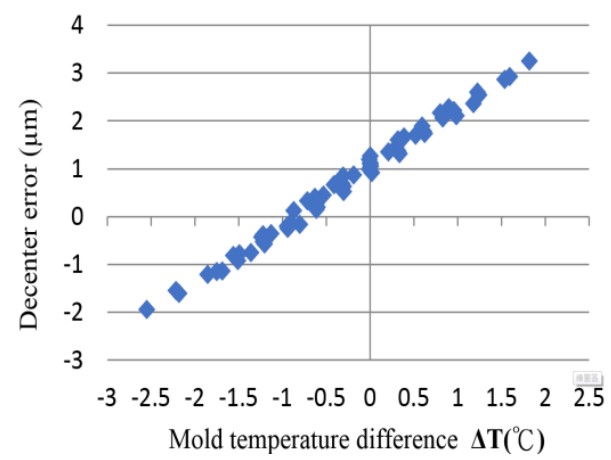

Fig. 15 Effect of mold temperature difference and decenter error.

\subsection{Fuzzy Control}

From the thermal expansion analysis, the optimum coolant temperature of the moved and fixed plate was $102.8{ }^{\circ} \mathrm{C}$ and $107.4{ }^{\circ} \mathrm{C}$, respectively. In the thermal coupling analysis, the initial coolant temperature of the moved and fixed plates was set at $102.8^{\circ} \mathrm{C}$ and $107.4{ }^{\circ} \mathrm{C}$, respectively. The boundary of the simulation was set as in Table 2, and the mold was preheated for $1 \mathrm{~h}$. The injection mold was simulated using thermal analysis for several shots until a stable temperature was reached, and the injection mold was interfered with $5 \mathrm{~min}$ of mold opening. After the mold temperature was altered and measured, a fuzzy control procedure was employed to obtain a new coolant temperature. The fuzzy control process is shown in Fig. 16.

The injection mold of the lens was simulated with multiple shots and a fuzzy control system was employed to compare the effects of these shots on coolant temperature (Figs. 17 and 18), mold temperature (Figs. 19 and 20), mold temperature difference (Fig. 21), and decenter error (Fig. 22). Without fuzzy control, the mold was closed and the temperature difference $\measuredangle \mathrm{T}$ ) is increased rapidly from- $-4.3{ }^{\circ} \mathrm{C}$ to $-1.4{ }^{\circ} \mathrm{C}$, but the mold temperature difference $\Delta \mathrm{T}$ ) did not reach the optimal range $\left(-0.5{ }^{\circ} \mathrm{C}\right.$ to $\left.-1{ }^{\circ} \mathrm{C}\right)$. After the second shot, the mold temperature difference gradually approached the optimal range, which was reached after nine shots. After the fuzzy control system was applied, when the mold temperature difference $(\Delta T)$ of $-4.3{ }^{\circ} \mathrm{C}$ was detected, the coolant temperature of the moved plate was increased, and the mold temperature

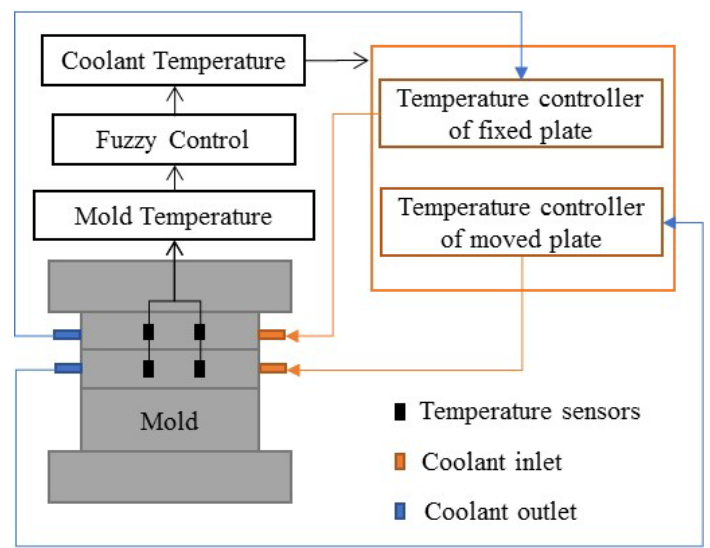

Fig. 16 Fuzzy control procedure.

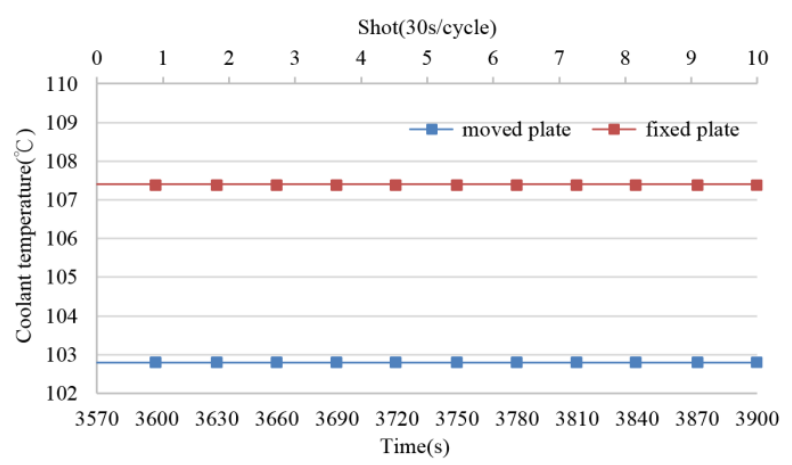

Fig. 17 Coolant temperature trends without fuzzy control.

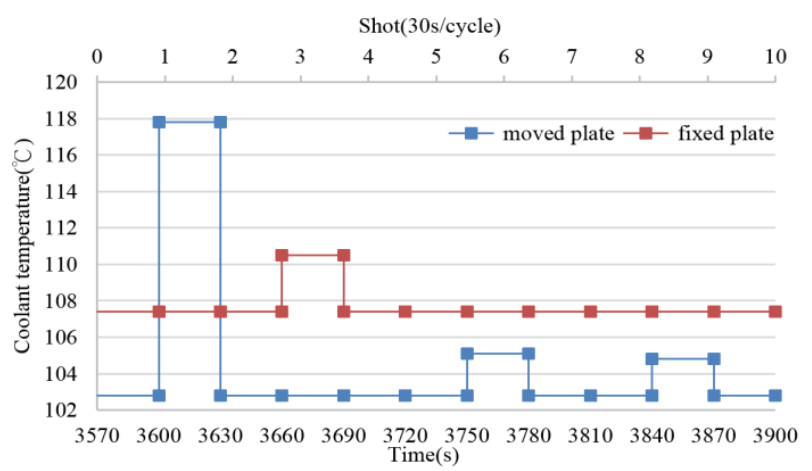

Fig. 18 Coolant temperature trend chart with fuzzy control.

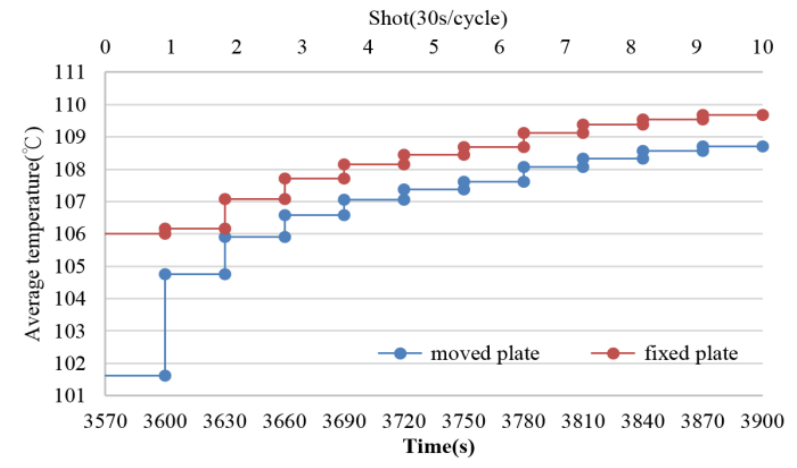

Fig. 19 Average mold temperature trends without fuzzy control. 


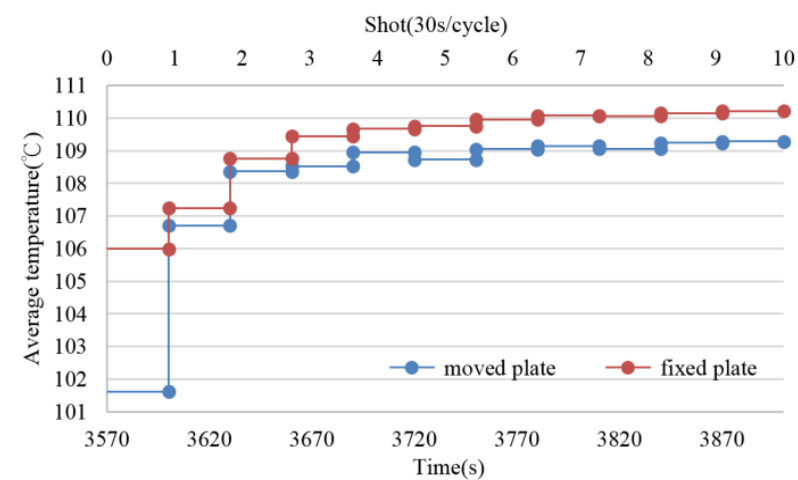

Fig. 20 Average mold temperature trends with fuzzy control.

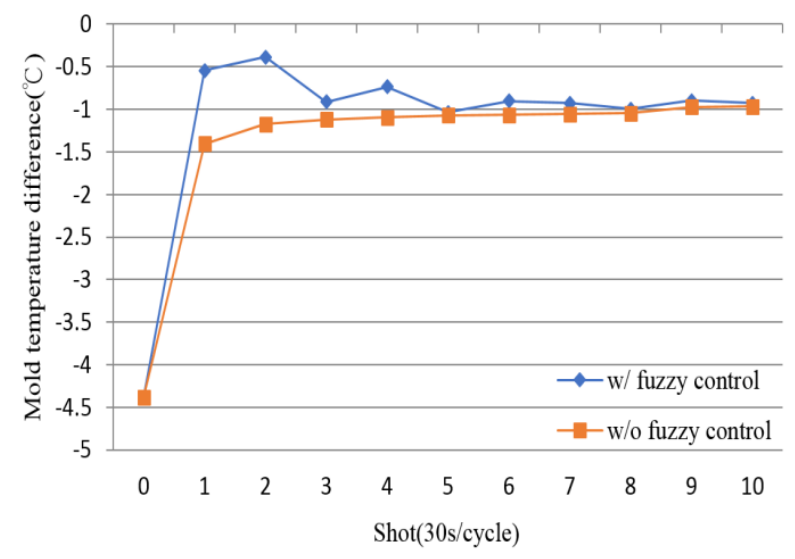

Fig. 21 Mold temperature difference trends.

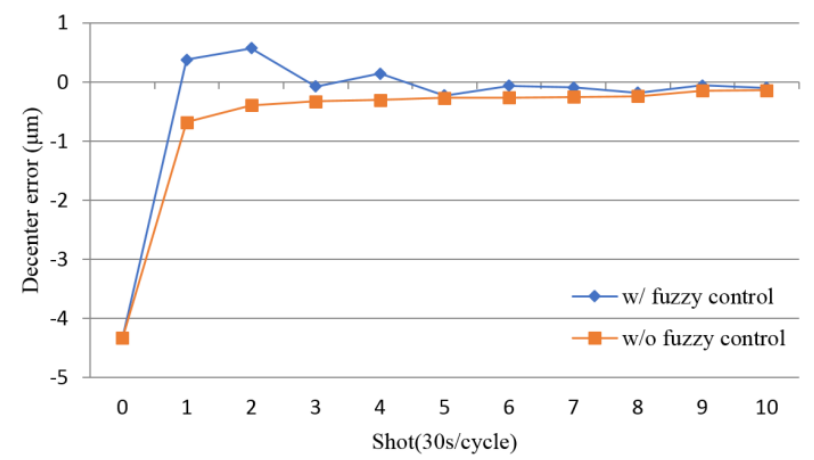

Fig. 22 Decenter error trends.

difference $(\Delta T)$ reached its optimal level during the first shot. The results revealed that applying a fuzzy control system can result in the mold temperature difference $(\Delta T)$ reaching its optimal level in a shorter period. When the fuzzy control system was not used, the decenter error was $0.3 \mu \mathrm{m}$ after 10 shots. By contrast, when the fuzzy control system was applied, the decenter error was $0.18 \mu \mathrm{m}$ after the same amount of shots. In this study, a fuzzy control system and thermal compensation technology were employed to obtain the optimal mold temperature quickly and mitigate the decenter error of a lens.

\section{Conclusions}

In this study, the displacement of the central axis of a lens was reduced through a simulation and fuzzy control thermal compensation system. The temperature of fixed and moved plate were modified to optimize the decenter value. The main findings of this study are as follows:

(1) According to Moldflow analysis, volume shrinkage was not the main factor affecting the decenter error of the studied aspherical plastic lens.

(2) The difference in thermal deformation between the fixed and moved plate was the main factor that caused this error.

(3) In aspherical plastic lens production, when the mold temperature difference $\measuredangle \mathrm{T}$ ) between the fixed and moved plate was controlled within the range of $-0.5{ }^{\circ} \mathrm{C}$ to $-1{ }^{\circ} \mathrm{C}$, the decenter error of the lens could be controlled within the range of $\pm 1 \mu \mathrm{m}$.

(4) The thermal compensation of the fuzzy control system was investigated to adjust the mold temperature difference $(\Delta \mathrm{T})$ in the range of $-0.5^{\circ} \mathrm{C}$ to $-1{ }^{\circ} \mathrm{C}$ quickly, and the decenter error caused by the unbalanced expansion of was reduced from 0.3 to 0.18 $\mu \mathrm{m}$. The quality of the lens could also be improved using this system.

\section{Acknowledgment}

We thank the National Science Council of Taiwan for funding this study.

\section{References}

[1] Carpenter, B., Patil, S., Hoffman, R., Lilly, B., and Castro, J. 2006. "Effect of Machine Compliance on Mold Deflection During Injection and Packing of Thermoplastic Parts.” Polymer Engineering and Science 46: 844-52.

[2] Juang, S. H., and Cheng, C. C. 2001. "Effect of Melt Temperature and Pressure on the Deformation of Magnesium Diecasting Dies.” Taiwan Mold and Die Industry Association. 
[3] Fu, C. H. 2010. "The Action of Stress on Displacement of Plastic Injection Mold.” Master thesis.

[4] Zadeh, L. A. 1965. Fuzzy Set, Information and Control 21, 338-53.

[5] Lee, C. C. 1990. "Fuzzy Logic in Control Systems: Fuzzy Logic Controller-Part I and Part II.” IEEE Trans. Syst. Man, Cybern. 20: 404-53.
[6] Sun, T. Y., and Yang, Y. K. 1997. Fuzzy Control, Chuan Hwa Publishing Ltd.

[7] Huang, C. C., Hung, S. M., Wu, W. W., Yang, Y. J., Chang, H. J., Chang, J. W., et al. 2012. "Application of Fuzzy Control to Improve Flow Balance of Multi-Cavity Hot Runner System.” Journal of Mechanics Engineering and Automation 2: 726-33. 